\title{
Toward an Adaptive Educational Hypermedia System (AEHS-JS) based on the Overlay Modeling and Felder and Silverman's Learning Styles Model for Job Seekers
}

\author{
https://doi.org/10.3991/ijet.v15i08.10574 \\ Aymane Qodad ${ }^{(凶)}$, Abdelilah Benyoussef, Abdallah El Kenz \\ Mohammed V University, Faculty of Sciences, Rabat, Morocco \\ Aymane2006@gmail.com \\ Mourad El Yadari \\ Moulay Ismail University, Meknes, Morocco
}

\begin{abstract}
In this paper we introduce a new design of an adaptive educational hypermedia system for job seekers, this proposal is based, for the part of learning objectives, on a job model which allows adapting the content and the path of education to the intended jobs, and, for the learner model construction, on a specific use of the learning styles of Felder and Silverman.

First, we present existing literature to give a general review on adaptive educational hypermedia systems, in that way; we have reported the related items to different notions in the adaptive educational Systems area as the differentiated pedagogy, the learning objects, and the learner profile. Then we argued our choice of the components of our model and we detailed the new ones.

As designed, the model can produce a suitable learning path for the user to match the job characteristics and the learning style of the person in order to help the user owning the job sought. With the possibility of linking the required competencies to the education skills, we aim to map business tasks to learning activities.

Based on this approach, we designed an Adaptive Educational Hypermedia System named AEHS-JS that will help to improve the efficiency and pragmatism of job search activities.

In plus of the social impact of this work as it help job seekers to complete their profiles and get the career they are looking for, this work will allow companies to find the candidates that match the job criteria sought.
\end{abstract}

Keywords-Adaptive educational hypermedia systems; learning object, learning styles, learning path, Overlay Modeling, differentiated instruction, Job model, Employability.

\section{Introduction}

Online learning is increasingly used in universities and schools; in this fastgrowing world, most e-learning systems do not yet make the business requirements as 
their priority. To meet this need Research has shifted to adaptive learning, which represents a domain of research in education in continuous development.

Traditional learning systems treats all users the same way, they deliver them the same content. When it comes to different people this way to do has shown its limits in terms of efficiency and effectiveness. The slogan "all things to all people" do not work.

There are several forms of adaptation, namely: adaptation based on user modeling, or those that use learning objectives to provide the learner with an education that fit with his profile [1]. So-called personalized Educational Hypermedia Systems are systems that use a methodology based on the objectives, preferences and knowledge of each, while adapting to their necessities [2]. In this way, a student in an adaptive educational model will be attribute a content that suit to his expertise on the theme.

Making personalized learning a big step towards improving online learning outcomes, but it is not enough because it does not take into account the needs of organizations and the learner's requirements. The purpose of learning is the knowledge of a learner who will contribute to the success of the learning process.

By working on this area, we are looking to suggest a new model that meets the business requirements to the learner part. The main goal is to set up an educational framework built on the work prerequisites and the user; this system will allow you to connect to the market.

We will begin the second section with a listing of related works. Then we will introduce the uses cases and the screenplay of the learning activity, thereafter in section four we will go through our model of Adaptive Educational Hypermedia System, we will zoom on the job model. To finish we will discuss the results, the conclusions, and draw some perspectives.

\section{$2 \quad$ Literature Review}

\subsection{The adaptive learning systems}

Recently, several studies have been interested in adaaptive learning systems that provide the suitable material in the appropriate way to the student by analyzing its profile (Figure 1), these methodologies may be classified into 3 categories:

The preferences category is related to models that define the education experience based on the learner preferences as the personality style. In this sense, we find the works of DeCoux [3], Maseleno [4], PRITCHARD [5], Savage [6] and TRUONG \& Huong [7].

These models uses and analyze the student behavior [8-9], observes it comportment [11-27], gives the user an online or mobile survey [12], [28], [14] and let him precise his choices and individual characters [15-16].

In our paper [10] we introduced a model based on the Felder and Silverman's learner styles to define the learner model and give the student a learning experience that meet the job needs. 
The second class, which is based in the user background and his knowledge, is considered as the most important feature for Adaptive Educational Hypermedia System [17].

This aspect can be represented in many ways. The first one is a rated System where we measure the degree of the learner knowledge in a domain by a rate (Exp.: a value between 0 and 5) or a grade (Exp: High, normal, lower,), this method is simple to implement but it remains insufficient for some innovative and adaptive techniques.

Besides this model, Overlay illustrate the learner data [18], this model allocates a numerical number, 0 or 1 , to every portion, showing the learner knowledge or not of an object.

The last category focus on the learner aims to select the suitable education experience for every single user.

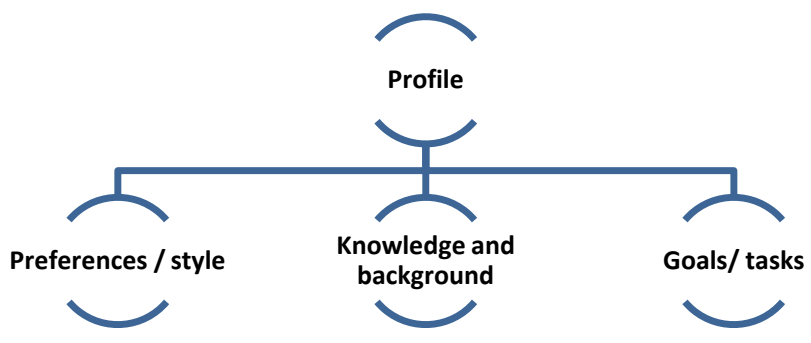

Fig. 1. The learner dimensions

Today, the challenge is not to bring people the knowledge and help them to fully learn it, the principal aim of education systems is to help learners to get the knowledge they need to get into the enterprise and and being able to satisfy the job requirement.

All of these systems make the learner model at the center of their models to establish the user learning experience, this make possible to adjust the path of education to the learner but does not allow thinking through the requirement of the business or the work opportunity we are targeting.

\subsection{The learning style model of silver man}

Several models in the literature have treated The Learning Style ([3] DeCoux [3], Maseleno [4], Pritchard [5] and Savage [6]).

In our case, we used the learning styles of Felder and Silverman and adapt it to our new model in order to have a system that bring the whole adaptation power. Indeed, we are leaning towards this choice for its easiness and its weight in the education researches [ 7 ] The model of Felder \& Silverman Learning Style is a questionary of 44-item that identifies the learner's learning style. In order to spare the heaviness of the survey in an education system intended to be accessible online, we have restricted the list of questions to 20 relevant ones that represent the main questions [23] 


\subsection{The differentiation in pedagogy}

In her research, Carol Ann explained the importance of differentiation in pedagogy, she based her conclusions on the fact that we cannot treat at a groupp of students in the sameway. The objective is to engage the learner in a challenging learning activities that enhance the the learning experience and build a system that take the student to higher level of compliance, This can be done over four ways: through content, the style of learning, product/process, and the background [32]., [24], in this work we focused on differencing the learning style and content, at the end, the result and environment are already known in an adaptive learning system.

The content: Adopting a strategy of differentiation at the content level consists on defining the learning objects list and organizing them in a number of ranks of knowledge and intellectual performance starting from lower-level intellectual expertise to higher-level. In our model we chosen the Taxonomy of Bloom (a grouping of 6 ranks comportment of intellectual starting by bottom-level intellectual abilities to higher-level). [25]

Therefore, we can build six different forms from one learning object; those new LO versions will be attributed to the student according to his score. By way of illustration, a student who has no experience in a domain will be given LOs with an inferior degree: memorizing and understanding, and a different one with some experience will receive learning objects for a higher level as applying and analyzing.

Learning styles: Every student has its favorite learning style, an important way of differencing is based on the provided support of education: it can be visual, auditory or written. Our choice in the model we want to apply is based on The Felder and Silverman's Learning Styles Model (see section III)

\section{Research Methodology}

In order to validate our model and reach our goals we based our research methodology on following instruments:

- Interviews with the human resources responsible for the job offers: this part of work will allow us to compare the results of different applicants and evaluate the value added of the learning experience on the process of selecting and recruiting candidates. It will bring us the result of each candidate and allow us to calculate the success rate. As the positions opened were only two in numbers, this part will bring us more information about each candidate independently of his results.

- A survey for the job seeker who have benefited from the learning experience, to collect quantitative data and their feedback. The survey is made up of 3 parts, the first one contain general instructions, the second specify the personal information (Gender, Age, years of experience...etc.), the third part is the body of the questionnaire where we gather candidate's opinion on the experience and the level of usefulness of the skills acquired by questions like : "what was the content that help you the most in the interview?" or a collect of opinion like : "The following items describe statements about the learning experience, please indicate your degree of 
agreement or disagreement about them: 1- The skills learned in the training helped me to convince the recruiter about my profile, 2-...etc." with 6 choices ( Strongly disagree, Disagree, Disagree somewhat, Agre somewhat, Agree, and Strongly Agree)

The participants were chosen from a list of 89 resumes received by the human resources responsible for the job offer. This task was done using a matching engine [35] to select resumes that match the most to the job need. The objective is to keep only the profiles that do not represent a big difference with the need.

In this study, we have limited our scope to a single job offer "Banking Business Analyst", the same process can be applied iteratively to a list of job offers.

A group of 23 candidates was selected to take the interviews with the job offer responsible. From this group, we have contacted some candidates to benefit from the learning experience based on our designed model.

In order to compare the result of the experience to a reference, we divided our group of 23 preselected candidate into two subgroups, the first one with 13 candidate to take the learning experience and the second with 10 candidates who will follow the normal interview process without any training experience.

In our study, the learning experience consists of the following main steps:

- Step I: The Job seeker authenticate in the system and fill in his account profile (individual data, competencies, CV...)

- Step II: The Job seeker response to a survey that determine his learner style

- Step III: He select the job he is looking for from the opened positions. (the model works for different job offers, but in this case we will focus on one job offer)

- Step IV: The system build a learning path that take into consideration both the job selected and the Job Seeker analyzed profile.

This learning path will lets the Job Seeker expand the competencies and befitted as the perfect applicant for the associated job.

Regarding the inductive part of our research, we established a new model of an adaptive learning system (cf. next section for more detail) that will be applied to the selected candidates.

\section{$4 \quad$ An Adaptation System For Job Seekers}

\subsection{Business and uses cases}

Before presenting the adaptation system architecture, we will start with a learning scenario, which represent the theoretical basis for the design of our system architecture; this scenario may take into consideration the job model, which is the principal component of our SHEA.

A job seeker who logs on to the system for the first time must complete a registration form including his resume and answer a survey that help us to determine his learning style and competencies. 
Thereafter, the job seeker selects one or more job offers that interest him / her, at this step our model is completed by the learning goals of the candidate, which is an important information for our system.

The learning experience is done through the pursuit of the learning path generated. Accordingly, it is possible to clearly distinguish three essential phases in the process of learning for a job:

- Registration form including the upload of resume

- Survey to determine the learning style

- The choice of a list of interesting job by the job seeker

- The system build content and learning path (matching the learner profile, the job wanted and the learning elements)

\subsection{The adaptation model}

The ALS (Adaptive Learning System) we designed is built with the following models:

- The Job Model

- The Domain model

- The Learner Model

- The Instruction Model

- and The Adaption Model (Fig. 2).

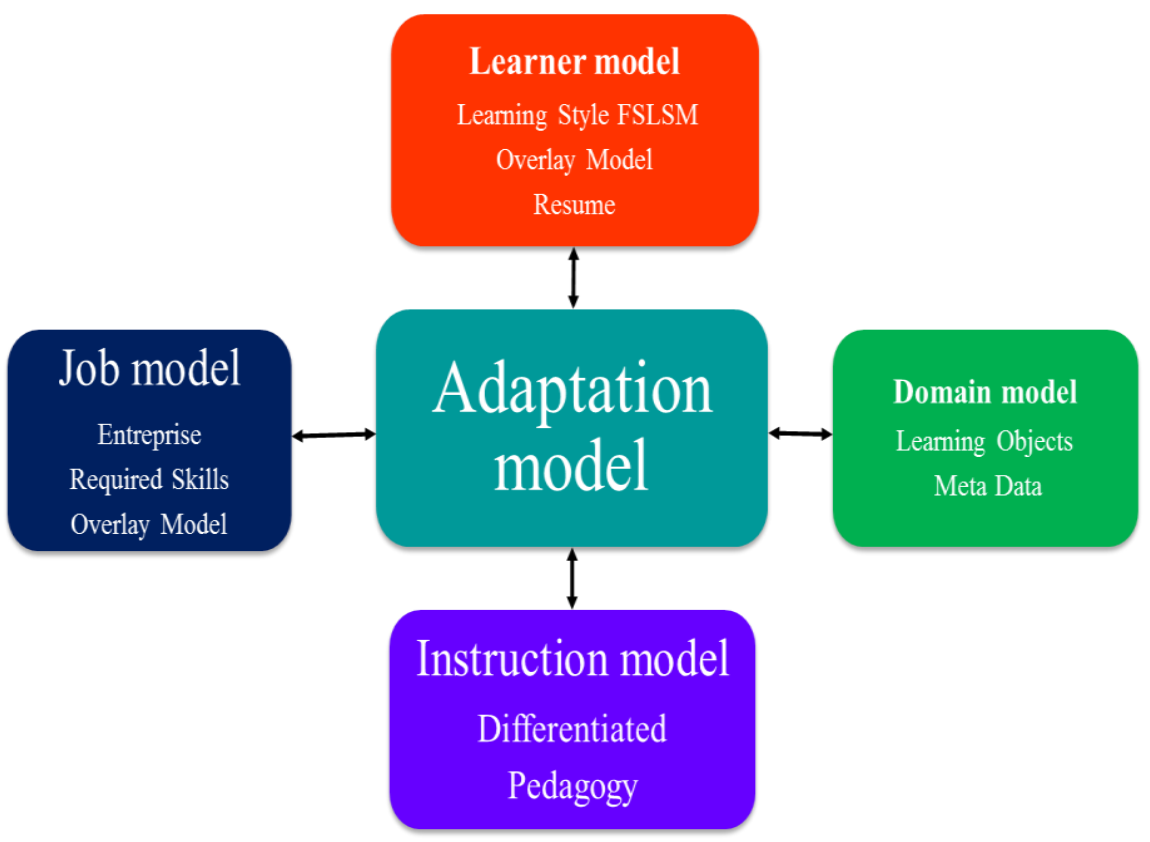

Fig. 2. Adaptation Model 
This global model is detailed by it components as below:

The Domain Model: This model is made of a universe of LOs (learning objects) based on the SCORM Principles, a various forms of an identical LOs and the metadata content as established by [21]

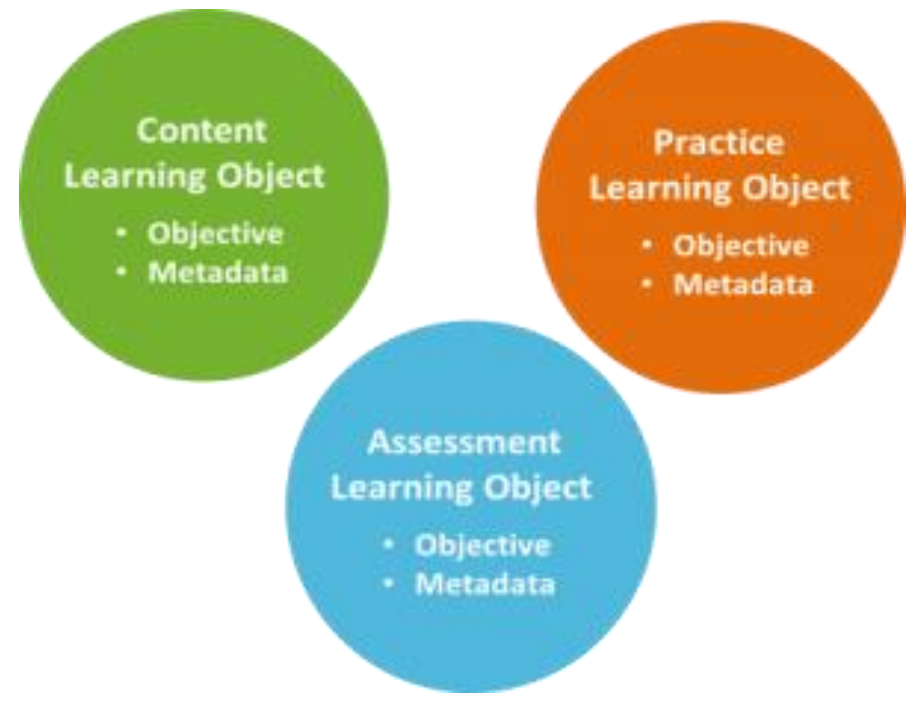

Fig. 3. Figure 1: Learning objects

As described by Robert BECK [28], the LO is "a collection of content items, practice items, and assessment items that are combined based on a single learning objective", in our case the learning objective is the job skills need.

We choose the learning objects for our domain model to prevent the "reinventing the wheel", it's a way to save time by reusing and sharing content to focus on specialized tasks and learning objects.

Our choice of SCORM standard will make the object reused in any learning management system or browser and easily manageable. In this standard, the learning object must comply with the Metadata of Learning objects LOM IEEE. The figure 1 in [34] describe the UML Class Diagram of IEEE LOM Metadata Standard.

In order to give an example of our learning objects, first we must specify our educational problem, in our case it is related to job we are looking for. Secondly, we will define the metadata to make our LO searchable in several search engines. Finally, we have to specify the requirement needed to be able to pursue the related LO.

Once the Learning Object's defined, our system have to choose between all indexed LOs in our Domain Model to propose to the learner the most suitable LO to his profile. Therefor we must build our Learner model that represent the profile of the learner.

The Learner Model: The learner model is set to define the Job seeker description, the learner model, as Brusilovsky [20] presented it, take 2 proportions, the major concern the data, and the other is based on the style of learner. 


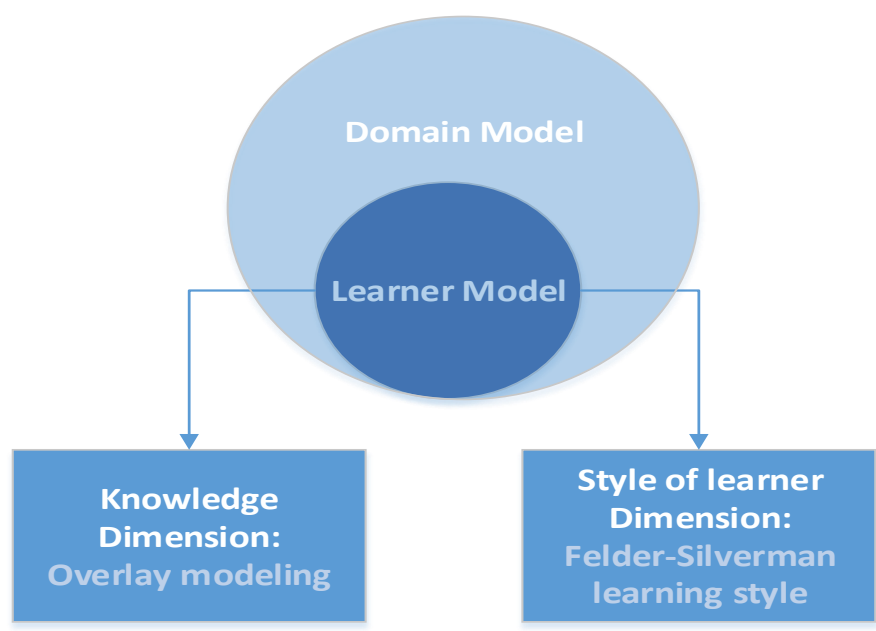

Fig. 4. Learner Model

In terms of data line, we used the model of overlay for the ease of setup and for the reason that it is a model that use a numerical value to qualify the degree of knowledge of an item. The principal notion of overlay modeling consist on considering the learner model a subgroup of domain model, and for all items in the model of learner (related to every item in the domain model) has a particular rate that quantify the learner's knowledge of this item. This rate is named the mastery of the item.

For each learner we define the level of mastery for a unit of course. It's can progress with the experience of learning and be evaluated based on the quizzes established. As shown in the table below: learners who obtain a result percentage less than 50 are classed as "Novice" and the level of mastery $M=1$. The other class $M=2$ is intermediate with percentage between 50 and 70 . The advanced one $M=3$ is reserved for learners who obtain a percentage greater than 70 . Only learners with a mastery of $\mathrm{M}=3$ degree can move to next level of topic.

The information about the learner model is warehoused in the database and will be used by the adaptation model to generate the learning path adequate to the learner.

Table 1. Learner level

\begin{tabular}{|l|l|c|}
\hline \multicolumn{1}{|c|}{ Level } & \multicolumn{1}{|c|}{ Score } & \multicolumn{1}{|c|}{ Mastery } \\
\hline Novice & $\mathrm{M}(\mathrm{X})<50$ & $\mathrm{M}=1$ \\
\hline Intermediate & $50<\mathrm{M}(\mathrm{X})<70$ & $\mathrm{M}=2$ \\
\hline Advanced & $70<\mathrm{M}(\mathrm{X})$ & $\mathrm{M}=3$ \\
\hline
\end{tabular}

The learner relational schema can be present as follow: 


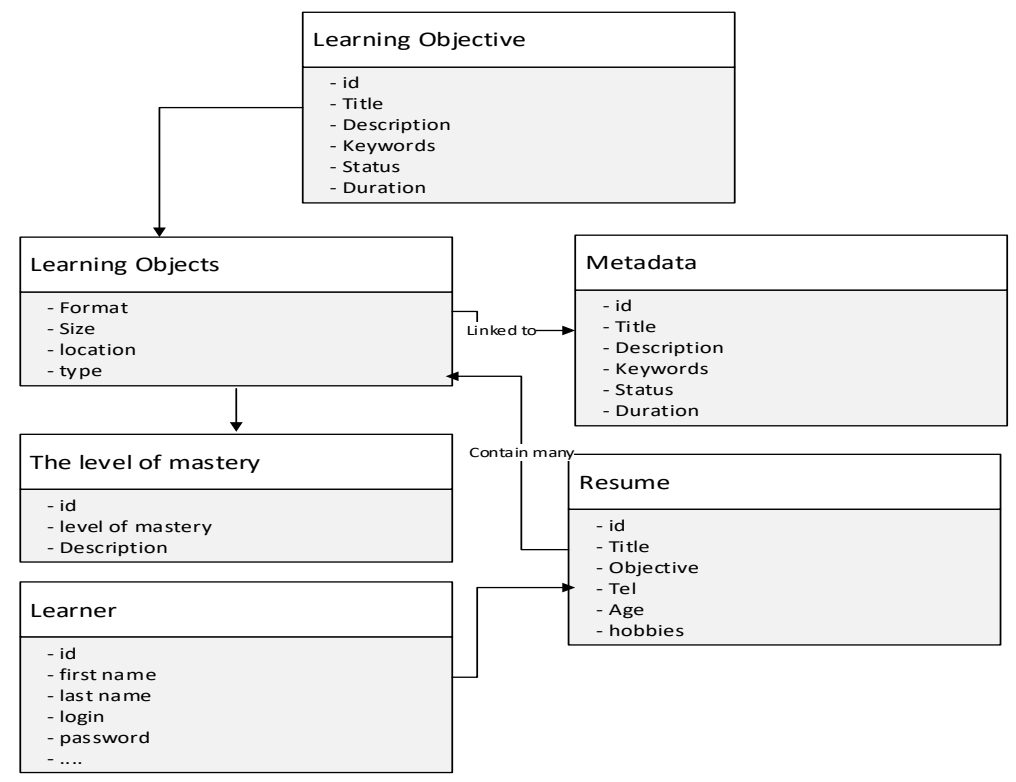

Fig. 5. Relationnel Schema for Learner

In practice, the proficiency of knowledge will be evaluated regarding the CV analysis of the student.

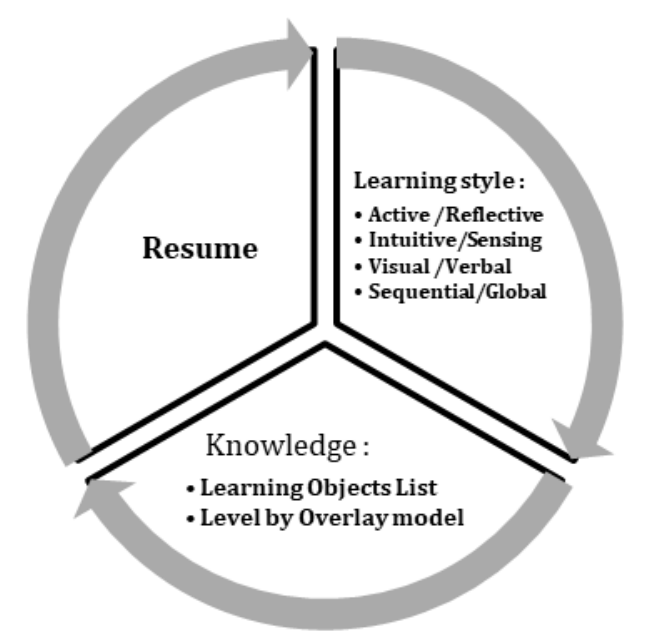

Fig. 6. Learner model components

For the learning style level, as we chosen the FSLS (Felder-Silverman learning style) model [22] (cf. sect. III) our relational model will contain the below classes, 
where the feeding of the learning style class linked to a learned is done by a resume data treatment and the result of the Felder and Silverman's Learning Styles test.

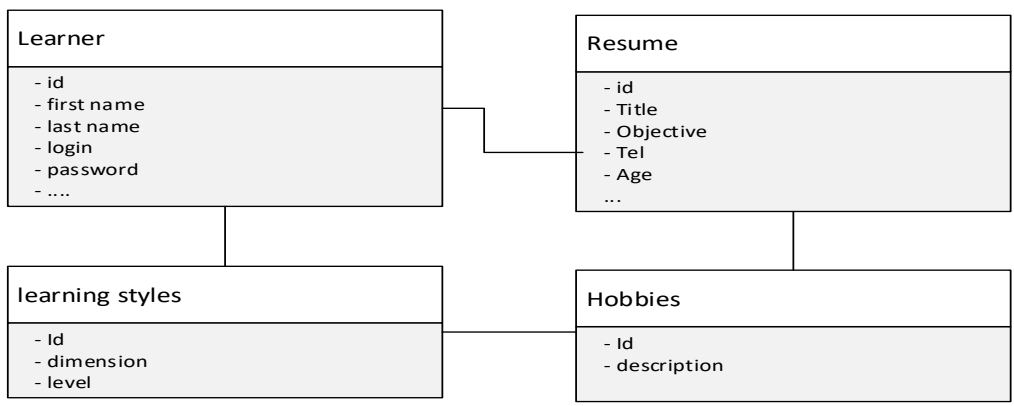

Fig. 7. Learning styles tables

Job Model: In this part we will define the job needs based on the list of skills and requirements that the person looking for this job must satisfy to get the job done.

This model organize and describe the business needs (in terms of jobs and offers). It connects between the components of business need (The Enterprise characteristics, the offer description, the looked-for profile, the wanted competencies, a competencies assessment...)

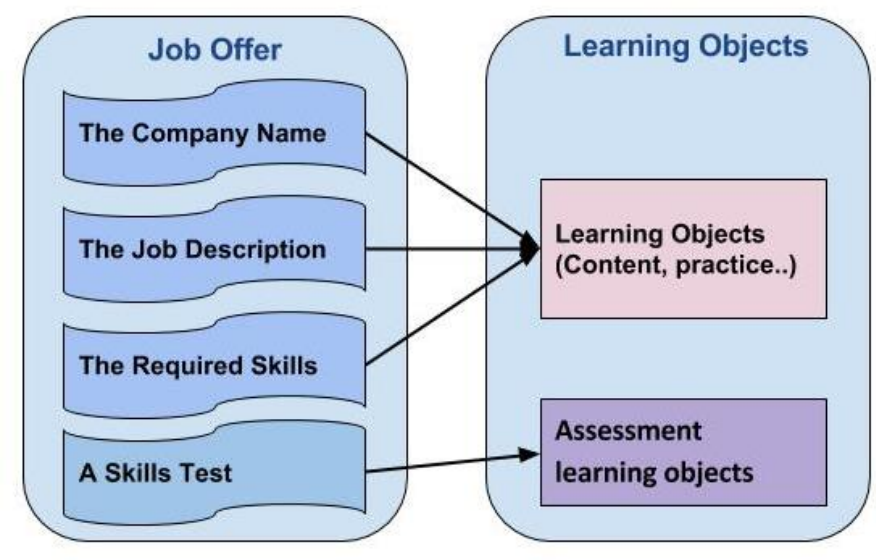

Fig. 8. The job model

The principal dimension of the job model concern the "required skills"; in this context, we have chosen the model named "overlay" to implement this component. It afford representing the information for learners in every subject in a adaptable approach.

The Overlay modeling is used to organize the knowledge by dividing the domain model into different concepts and subjects, this approach allow educational AHS. 
The advantage of using an identical system to characterize the knowledge notion in job and learner models will help for the correspondence processing in the adaptation model. In the same way established in learner model, we use the overlay model to characterize the required skills by a Job offer. At the level of the job model we define for every unit of course the level of mastery needed. It's can be liked to a job description to categorize a group of job offers (cf. table 2 below).

The information about the Job model is stored in the database and will be used by the adaptation model to generate the learning path adequate to the job wanted.

Table 2. unit mastery required

\begin{tabular}{|l|l|c|}
\hline \multicolumn{1}{|c|}{ Unit of course } & \multicolumn{1}{|c|}{ Job description } & Mastery required \\
\hline Unit 1 & Project Manager & $\mathrm{M}=3$ \\
\hline Unit 2 & Software engineer & $\mathrm{M}=1$ \\
\hline Unit 3 & English Professor & $\mathrm{M}=2$ \\
\hline
\end{tabular}

The job offer relational schema can be present as follow:

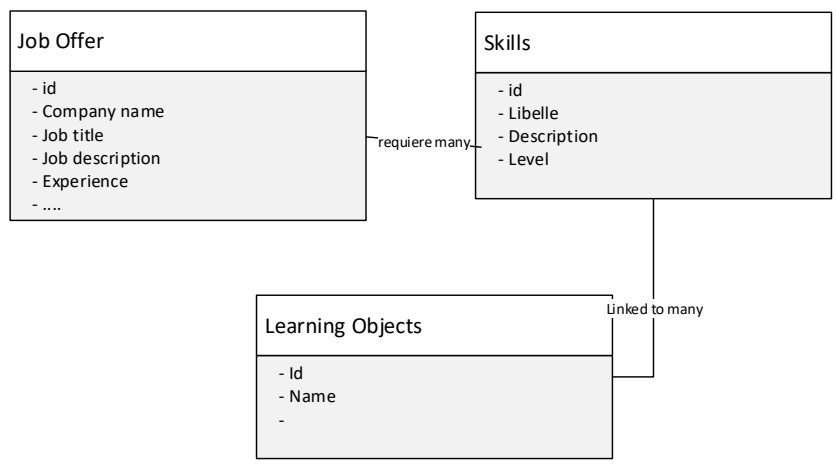

Fig. 9. Job Offer relationnel Schema

Instructional model: The model of instruction define the education strategy adopted to allocate the LOs existing and organized in the model of domain. In this global model we chosen the differentiated pedagogy for the possibilities its offer in terms of adjusting of the instruction at the different levels as the content, the process or the learning materiel (Cf. Sect. IV)

Adaptation model: The adaptation model represent our engine that to define the list of LOs based on the analyze of learner profile (Mastery, LS) and the details of the chosen employement (necessary competencies...), the main work consist on assigning LOs that tie with the required skill by the business (job offer) and the learner characteristic. (Cf. Fig. 2). 


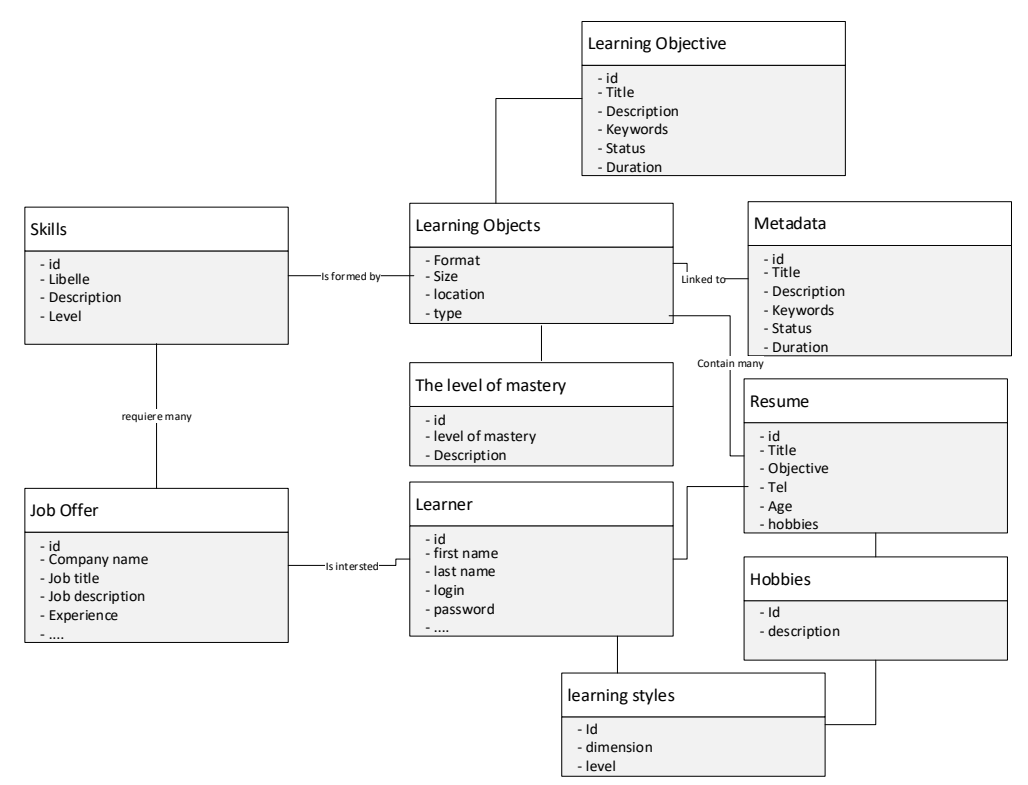

Fig. 10.The Adapatation relationnel schema

In order to determine the list of learning objects and to define the learning path for the learner, we eliminate the LOs list assimilated by the candidate from the required by the job offer. As the LOs are designed into the same model (domain model) this subtraction can be modeled in its standard form under the following mathematical formula:

$$
\sum_{k=0}^{n} \operatorname{Final}(L O S)=\sum_{k=0}^{n} \operatorname{Required}(L O S)-\sum_{k=0}^{n} \operatorname{Acquired}(\mathrm{LOS})
$$

Where,

LOs: The Learning Objects list. This list must contains the metadata related to LS of the candidate.

Final (LOs): The final list that will be used in the learning experience.

Required (LOs): The LOs list necessary in the job offer

Acquired ( $L O s$ ): The Learning objects list already learned by the Student (in our case: the job seeker). 


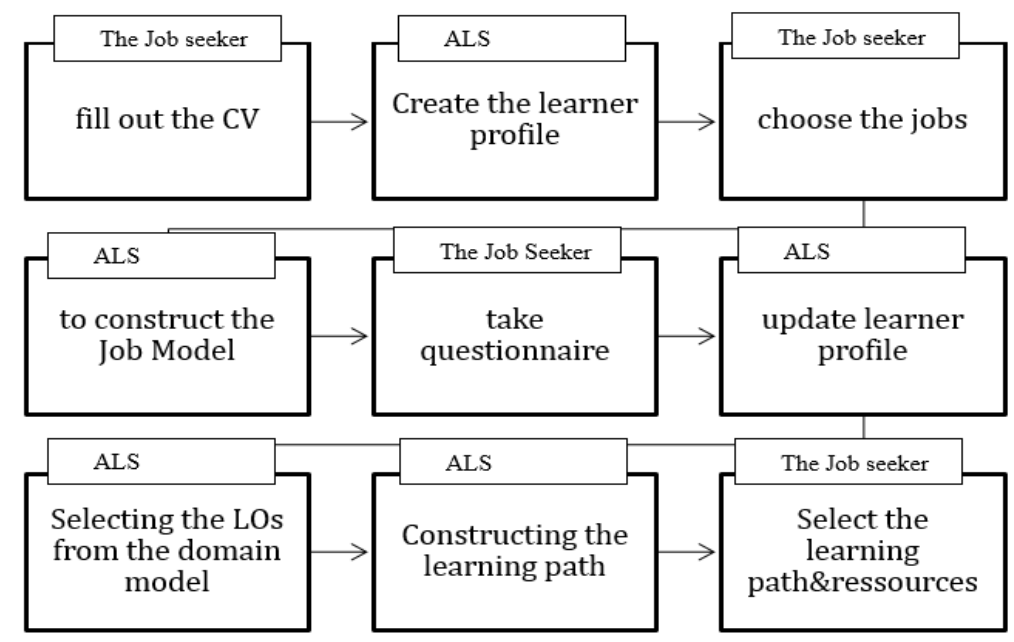

Algorithms principal steps:

\section{BEGIN}

Step 1: Filling the learner data from CV and skills tests: $\mathrm{M}(\mathrm{X})=\sum \mathrm{MLi}$ where $i=$ competency acquiered by the learner and MLi = level of mastery of the competency Skills $\mathrm{M}(\mathrm{X})=\sum \mathrm{Skills} / \mathrm{mastery}$ level $=\sum \mathrm{MLi}$

Step 2: take survey to define the learning style Learning style LS $(X)=$ LSi

Step 3: filling the job model data based on the job description chosen

Job description $=\sum \mathrm{MLj}$ where $j=$ competency required by the job

Step 4: generating the LP(learning path) established on the model of job and selecting the learning objects from the domain model

Initiate the unit number $u=1$

Initiate content level $l=1$

Initiate learner level = MLi (based on the model of learner)

Step 5: take the learning experience (courses and assessments of unit u)

Present the unit $u$

If the skill test related to the unit $\mathrm{u} M(\mathrm{Xu})>\mathrm{MLu}$

go to next unit $u=u+1$

Else present unit $u$ with level $=1+1$

Go to step 5

Step 6: update the learner model 


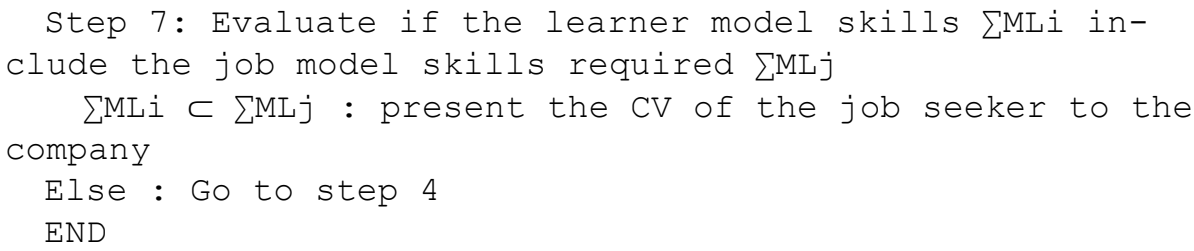

\section{$5 \quad$ Results}

Survey Results: To validate our model of learning designed for job seekers, we explored the results of the survey taken by the candidates.

Regarding the impact of the training on the interview process, we received the response detailed in the table 3

Table 3. The usefulness of the skills acquired in training in interviews

The skills learned in the training helped you to convince the recruiter about your profile?

\begin{tabular}{|l|c|}
\hline Strongly disagree & $7 \%$ \\
\hline Disagree & $13 \%$ \\
\hline Disagree somewhat & $5 \%$ \\
\hline Agree somewhat & $7 \%$ \\
\hline Agree & $40 \%$ \\
\hline Strongly agree & $28 \%$ \\
\hline
\end{tabular}

Furthermore, $69 \%$ of candidates who agreed or strongly agreed on the usefulness of skills learned in the training have a number of years of experience less than 4 years.

The table 4 shows the results related to most useful skill acquired for the interview process.

Table 4. The usefulness of the skills acquired in training in interviews

\begin{tabular}{|l|c|}
\hline \multicolumn{2}{|c|}{ The most useful Skill learned by the job seeker for the interview } \\
\hline Banking functional & $43 \%$ \\
\hline Project management fundamentals & $28 \%$ \\
\hline Business Analyst CCBA & $17 \%$ \\
\hline Communication & $8 \%$ \\
\hline Others & $4 \%$ \\
\hline
\end{tabular}

It was found that candidates who qualified themselves as adapted to the position were more satisfied about the experience and had less difficulty reported in the interview process.

The result shows us that more than $70 \%$ of candidates were in favor of repeating the experience or recommending the learning to other people.

Interviews Results: Through the 23 candidates preselected for the job interview process, two candidates were admitted to the position; both of them had completed the learning experience. 
Furthermore, the interview results shows that appreciations of eight candidates qualified them to be accepted if there were more opened positions. Six of these candidates were in the list who completed the learning experience.

The 13 candidates who passed the learning experience were better rated in all major required skills except "communication" where the rest was slightly better appreciated; these candidates demonstrated greater enthusiasm for the position than others were.

The job offers responsible mentioned that some candidates declared that they had followed a training for the interview and he appreciated this.

Table 5. Interviewers' statements revealed some remarkable feedbacks on candidates (table 5).

\begin{tabular}{|l|l|}
\hline \multicolumn{1}{|c|}{ Candidate } & \multicolumn{1}{|c|}{ Statement on the candidate } \\
\hline M, B & $\begin{array}{l}\text { He is certified in project management, he has good communication } \\
\text { skills but it is clear that he is not motivated by the position. }\end{array}$ \\
\hline G. L & $\begin{array}{l}\text { He has demonstrated knowledge of the field, he is certainly not an } \\
\text { expert but he will be able to satisfy the job needs }\end{array}$ \\
\hline M. A & $\begin{array}{l}\text { The candidate M.A is very motivated for the position, he has some } \\
\text { communication difficulties, he has a lot of potential and masters project } \\
\text { management and business analysis approach }\end{array}$ \\
\hline Y. B & $\begin{array}{l}\text { The profile is interesting, he can support us in the training of new } \\
\text { recruits, but he shows that he has never practiced project management } \\
\text { in operating conditions; it will take him a little time to master the } \\
\text { project approach. }\end{array}$ \\
\hline
\end{tabular}

Generally, results shows that the interviewers were more interested by the profiles who did the training. In deed, they qualified them like more "interesting", "fitting to the job", "motivated", and "initiated in the domain".

\section{Discussions}

The main goal of this work was to set up a system that help job seekers to boost their chances to get the position they are looking for.

Based on the results, the adaptive learning system designed for the job seekers, improved the employability related to the job offer in question by $56 \%$, indeed, The effectiveness of the system was also confirmed by the candidates feedbacks who reported the utility of the education content as it helped them to gain greater profile and showcase their competencies.

These findings confirm the works of $\mathrm{Ng}$ and Feldman, [36] and Krueger \& Rouse [37], on how positively education is influencing core task performance and employability.

Seeing that the majority of candidates who were satisfied by the experience are junior is interesting, this can be explained by the fact that this category of candidates is still in touch with education, and regarding their experience, they are the ones who needs the most such as learning experience.

It is normal that the impact of the system was more visible on some skills than others, indeed, some skills like communication and relationship management needs more 
time and practice to see significant results, the system shows more efficiency on knowledge skills like functional banking or management. This finding shows the limitation of our model on some particular skills, but it will not impede us to include these type of elements in our content, because for some candidate who have a minimum of level on this type of skill, the result can be more interesting. These results support the studies of [36] where they classified the knowledge into two form, the declarative knowledge that can be learned based on suitable content and the procedural one that need more practice.

The system is more efficient for persons who are initiated in the fields, this can be explained by the reason that qualified people are more able to understand concept that are related to what they master.

The results of the interviews with the persons in charge of the recruitment brought out that they were aware that some candidates have followed a training, and they valued it positively. This statement drives us to explore the opportunity of applying this system within the companies during the integration of new recruits.

To sum up, this work showed us the importance of education in improving the employability of job seekers, and how can a job-oriented learning lead us to better results, these comply with different studies carried out in this field [38, 39, 40].

\section{$7 \quad$ Limitations}

As with all studies, there are limitations. In our case, we applied our model on one job offer and collect data related to the job seekers looking for this job, this can be done for other jobs and different populations to make our work more global and confirm the generalizability of the finding.

\section{Conclusion and Future Works}

Online learning provide people a new way to improve their skills in different area, In our case we focused on it use to enhance job seekers chances to satisfy the jobs requirements. Study have revealed the role of education in employment and job performance. In this work, we designed an Adaptive Educational Hypermedia System for Job Seekers "AEHS-JS" to evaluate the utility of job oriented education on increasing the employability and job performance.

We used for this work the Overlay Modeling and Felder and Silverman's Learning Styles Model for Job Seekers. Our model is based on two principals element, the first one is the model of learner and the second one is the job model, the main goal is to establish a learning experience able to make the student fits more to the profession he is looking for. By this approach, we are ensuring the link between learning systems and business requirements. The challenge is to build a system based on this model that works for businesses and job seekers both.

Like many studies, the results of our work confirm the importance of education in improving employment opportunities, a job oriented education can in enhance chances of succeeding for a job seeker by more than a half ( in a similar context of the one 
used in our test case). Moreover, even job seekers who did not succeed the opened position were interested in the experience for other job offers in future.

The same model can be used by companies to build a training program that help employees evolve from one position to another by pursuing an individual training plan. The next step will consist on working on a probabilistic approach of adaptation based on Bayesian Network with a new step added to the learning path "* revaluation of the learning path". This will be useful for the implementation and will allow trying out another adaptation algorithm and more data collection on different populations.

\section{Acknowledgement}

We would like to thank the recruiting team who made the effort to provide their feedback on this model as well as the candidates who willingly agreed to give their time and participate in the learning experience.

\section{References}

[1] Brusilovsky, Peter, and Eva Millán. "User models for adaptive hypermedia and adaptive educational systems." The adaptive web. Springer-Verlag, 2007. https://doi.org/10.1007/ 978-3-540-72079-9_1

[2] Tsortanidou, X., Karagiannidis, C., \& Koumpis, A. (2017). Adaptive Educational Hypermedia Systems based on Learning Styles: The Case of Adaptation Rules. International Journal of Emerging Technologies in Learning, 12(5). https://doi.org/10.3991/ijet.v12 i05.6967

[3] DeCoux, V. M. (2016). Kolb's learning style inventory: A review of its applications in nursing research. Journal of Nursing Education, 29(5), 202-207. https://doi.org/10.3928/ 01484834-19900501-04

[4] Maseleno, A., Hardaker, G., Sabani, N., \& Suhaili, N. (2016). Data on multicultural education and diagnostic information profiling: Culture, learning styles and creativity. Data in brief, 9, 1048. https://doi.org/10.1016/j.dib.2016.11.024

[5] Pritchard, A. (2017). Ways of learning: Learning theories for the classroom. Routledge.

[6] Savage, K., Arif, S., Smoke, M., \& Farrell, T. (2017). Preferences in learning styles and modes of information delivery in patients receiving first-day education for radiation therapy. Journal of medical imaging and radiation sciences, 48(2), 193-198. https://doi.org/10. 1016/j.jmir.2016.10.011

[7] Truong, H. M. (2016). Integrating learning styles and adaptive e-learning system: Current developments, problems and opportunities. Computers in human behavior, 55, 1185-1193. https://doi.org/10.1016/j.chb.2015.02.014

[8] Clark, R. C., \& Mayer, R. E. (2016). E-learning and the science of instruction: Proven guidelines for consumers and designers of multimedia learning. John Wiley \& Sons. https ://doi.org/10.1002/9781119239086

[9] Özyurt, Ö., \& Özyurt, H. (2015). Learning style based individualized adaptive e-learning environments: Content analysis of the articles published from 2005 to 2014. Computers in Human Behavior, 52, 349-358. https://doi.org/10.1016/j.chb.2015.06.020

[10] Qodad, A., Seghroucheni, Y. Z., Al Achhab, M., El Yadari, M., El Kenz, A., \& Benyoussef, A. (2016, October). An adaptive learning system based on a Job model, the 
differentiated instruction and Felder and Silverman's learning styles model. In 2016 4th IEEE International Colloquium on Information Science and Technology (CiSt) (pp. 506510). IEEE.. https://doi.org/10.1109/cist.2016.7805100

[11] Graf, S., \& Ives, C. (2010, July). A flexible mechanism for providing adaptivity based on learning styles in learning management systems. In 2010 10th IEEE International Conference on Advanced Learning Technologies (pp. 30-34). IEEE. https://doi.org/10.1109/i calt. 2010.16

[12] Klašnja-Milićević, A., Vesin, B., Ivanović, M., \& Budimac, Z. (2011). E-Learning personalization based on hybrid recommendation strategy and learning style identification. Computers \& Education, 56(3), 885-899. https://doi.org/10.1016/j.compedu.2010.11.001

[13] Matthews, K., Janicki, T., He, L., \& Patterson, L. (2019). Implementation of an automated grading system with an adaptive learning component to affect student feedback and response time. Journal of Information Systems Education, 23(1), 7.

[14] Normadhi, N. B. A., Shuib, L., Nasir, H. N. M., Bimba, A., Idris, N., \& Balakrishnan, V. (2019). Identification of personal traits in adaptive learning environment: Systematic literature review. Computers \& Education, 130, 168-190. https://doi.org/10.1016/j.compedu. 2018.11.005

[15] Jensen, J. (2019). A systematic literature review of the use of Semantic Web technologies in formal education. British Journal of Educational Technology, 50(2), 505-517. https:// doi.org/10.1111/bjet.12570

[16] Tadlaoui, M. A., Aammou, S., Khaldi, M., \& Carvalho, R. N. (2016). Learner modeling in adaptive educational systems: a comparative study. International Journal of Modern Education and Computer Science, 8(3), 1. https://doi.org/10.5815/ijmecs.2016.03.01

[17] Brusilovsky, P., \& Millán, E. (2007). User models for adaptive hypermedia and adaptive educational systems. In The adaptive web (pp. 3-53). Springer, Berlin, Heidelberg. https:// doi.org/10.1007/978-3-540-72079-9_1

[18] Nguyen, L., \& Do, P. (2009, May). Combination of Bayesian network and overlay model in user modeling. In International Conference on Computational Science (pp. 5-14). Springer, Berlin, Heidelberg.

[19] García-Peñalvo, F. J., Fidalgo-Blanco, Á., \& Sein-Echaluce, M. L. (2018). An adaptive hybrid MOOC model: Disrupting the MOOC concept in higher education. Telematics and Informatics, 35(4), 1018-1030. https://doi.org/10.1016/j.tele.2017.09.012

[20] Chen, Y., Li, X., Liu, J., \& Ying, Z. (2018). Recommendation system for adaptive learning. Applied psychological measurement, 42(1), 24-41.

[21] Seghroucheni, Yassine Zaoui, and Badr Eddine El Mohajir. "A Recommendation System Operating after Assessment to Correct Learning Paths in a Content Adapting System." International Journal of Computer Applications 93.13 (2014). https://doi.org/10.5120/16 279-6061

[22] Felder, Richard M., and Linda K. Silverman. "Learning and teaching styles in engineering education." Engineering education 78.7 (1988): 674-681.

[23] Graf, Sabine, Silvia Rita Viola, and T. Leo Kinshuk. "Representative characteristics of felder-silverman learning styles: An empirical model."Proceedings of the IADIS International Conference on Cognition and Exploratory Learning in Digital Age (CELDA 2006), Barcelona, Spain. 2006.

[24] Lynch, S. D., Hunt, J. H., \& Lewis, K. E. (2018). Productive struggle for all: Differentiated instruction. Mathematics Teaching in the Middle School, 23(4), 194-201. https://doi.org/ 10.5951/mathteacmiddscho.23.4.0194

[25] Verenna, A. M. A., Noble, K. A., Pearson, H. E., \& Miller, S. M. (2018). Role of comprehension on performance at higher levels of Bloom's taxonomy: Findings from assessments 
of healthcare professional students. Anatomical sciences education, 11(5), 433-444. https ://doi.org/10.1002/ase. 1768

[26] Silvia Schiaffino, Patricio Garcia, Analia Amandi, E-teacher providing personalized assistance to e-learning students? SISTAN Research Institute Fac. Cs. Exactas - UNCPBA, Campus Universitario, Paraje Arroyo Seco, 7000 Tandil, Buenos Aires, Argentina, 2008.

[27] Verenna, A. M. A., Noble, K. A., Pearson, H. E., \& Miller, S. M. (2018). Role of comprehension on performance at higher levels of Bloom's taxonomy: Findings from assessments of healthcare professional students. Anatomical sciences education, 11(5), 433-444. https ://doi.org/10.1002/ase.1768

[28] Papadakis, S., Kalogiannakis, M., Sifaki, E., \& Vidakis, N. (2017). Access moodle using smart mobile phones. A case study in a Greek University. In Interactivity, Game Creation, Design, Learning, and Innovation (pp. 376-385). Springer, Cham. https://doi.org/10.1 007/978-3-319-76908-0_36

[29] Papadakis, S., Kalogiannakis, M., Sifaki, E., \& Vidakis, N. (2018). Evaluating Moodle use via Smart Mobile Phones. A case study in a Greek University. EAI Endorsed Trans. Creative Technologies, 5(16), e1. https://doi.org/10.4108/eai.10-4-2018.156382

[30] Papadakis, S. (2018). Evaluating pre-service teachers' acceptance of mobile devices with regards to their age and gender: a case study in Greece. IJMLO, 12(4), 336-352. https:// doi.org/10.1504/ijmlo.2018.095130

[31] Kalogiannakis, M., \& Papadakis, S. (2019). Evaluating pre-service kindergarten teachers' intention to adopt and use tablets into teaching practice for natural sciences. International Journal of Mobile Learning and Organisation, 13(1), 113-127. https://doi.org/10.1504/ ijmlo.2019.10016617

[32] Kalogiannakis, M., \& Papadakis, St. (2007). The dual form of further education of educators in ICT: technological and pedagogical training. In C. Constantinou, Z. Zacharias \& M. Papaevripidou (Eds.) Proceedings of the 8th International Conference On Computer Based Learning in Science, Heraklion, 30 June - 6 July 2007, 265-276.

[33] Kikilias, P., Papachristos, D., Alafodimos, N., Kalogiannakis, M. \& Papadakis, St. (2009). An Educational Model for Asynchronous E-Learning. A case study in a Higher Technology Education, In D. Guralnick (ed.) Proceedings of the International Conference on ELearning in the Workplace (ICELW-09), 10-12 June 2009, New York: Kaleidoscope Learning (CD-Rom). https://doi.org/10.3991/ijac.v3i1.987

[34] Ciloglugil, B., \& Inceoglu, M. M. (2016, April). Ontology usage in e-learning systems focusing on metadata modeling of learning objects. In International Conference on New Trends in Education, ICNTE (pp. 80-96).

[35] Aymane Qodad, A. El Kenz, A. Benyoussef, and M. El Yadari. 2019. An Adaptive Learning System based on a matching Jobs and Resumes Engine. In Proceedings of the 4th International Conference on Big Data and Internet of Things (BDIoT'19). Association for Computing Machinery, New York, NY, USA, Article 71, 1-7. https://doi.org/10.1145/3 $\underline{372938.3373009}$

[36] Ng, T. W., \& Feldman, D. C. (2009). How broadly does education contribute to job performance?. Personnel psychology, 62(1), 89-134. https://doi.org/10.1111/j.1744-6570 $.2008 .01130 . \mathrm{x}$

[37] Krueger, A., \& Rouse, C. (1998). The effect of workplace education on earnings, turnover, and job performance. Journal of Labor Economics, 16(1), 61-94. https://doi.org/10.1086/ $\underline{209882}$

[38] Ishola, A. A., Adeleye, S. T., \& Tanimola, F. A. (2018). Impact of educational, professional qualification and years of experience on accountant job performance. Journal of Accounting and Financial Management, 4(1), 32-44. 
[39] Anam Amin, R. S., \& Lodhi, M. R. N. (2013). The impact of employees training on the job performance in education sector of Pakistan. Middle-East Journal of scientific research, 17(9), 1273-1278.

[40] Bishop, J. (1992, December). The impact of academic competencies on wages, unemployment, and job performance. In Carnegie-Rochester Conference Series on Public Policy (Vol. 37, pp. 127-194). North-Holland. https://doi.org/10.1016/0167-2231(92)90006-5

\section{Authors}

Aymane Qodad, Abdelilah Benyoussef and Abdallah El Kenz work at

Mohammed V University as Faculty of Sciences in Rabat, Morocco. Aymane Q is the corresponding author.Aymane2006@gmail.com

Mourad El Yadari works for Moulay Ismail University in Meknes, Morocco.

Article submitted 2019-03-31. Resubmitted 2020-01-23. Final acceptance 2020-01-24. Final version published as submitted by the authors. 